\title{
Classroom-based professional expertise: a mathematics teacher's practice with technology
}

\author{
Gulay Bozkurt ${ }^{1,2} \cdot$ Kenneth Ruthven $^{1}$
}

Published online: 19 October 2016

(C) The Author(s) 2016. This article is published with open access at Springerlink.com

\begin{abstract}
This study examines the classroom practice and craft knowledge underpinning one teacher's integration of the use of GeoGebra software into mathematics teaching. The chosen teacher worked in an English secondary school and was professionally well regarded as an accomplished user of digital technology in mathematics teaching. Designed in accordance with the Structuring Features of Classroom Practice framework (Ruthven, 2009), the study triangulates evidence from lesson observations and post-lesson interviews to analyse how this teacher's classroom practice and professional knowledge support the integration of technology. This analysis shows how the teacher managed a number of aspects of classroom teaching related to using GeoGebra such as including technology-mediated tasks aligned with his pedagogical goals, preparing his students to use the technology efficiently, adapting formats for classroom activity and extending his curriculum scripts for the topics studied.
\end{abstract}

Keywords Classroom practice $\cdot$ Mathematics teaching $\cdot$ Dynamic mathematics software Technology use $\cdot$ Professional expertise $\cdot$ Craft knowledge

\section{Introduction}

Researchers have started to examine the professional learning which accompanies the uptake of new technologies into education, arguing that the process of teaching technology-integrated mathematics lessons calls for "change in teachers' professional knowledge" (Gueudet \& Trouche, 2009, p. 199). Studies have shown that, over time, professional growth takes place as teachers adapt and revise their practices in working with technology through feedback from their classroom experience (e.g., Abboud-Blanchard, 2014; Drijvers, 2012; Haspekian, 2014; Monaghan, 2004). In other words, an important way in which teachers' knowledge develops is

Gulay Bozkurt

glybzkrt@gmail.com

1 Faculty of Education, University of Cambridge, Cambridge, UK

2 Eskisehir Osmangazi University, Eskisehir, Turkey 
through their responses to practical challenges thrown up by their use of digital tools and through their reflection on the efficacy of these responses. In particular, Tabach (2012) has drawn attention to an interaction between knowledge and practice which underpins technology integration in mathematics teaching, with change in practice fostering growth of knowledge and vice versa.

The value of researching the "craft knowledge" of expert teachers has long been recognised (e.g., Leinhardt, 1988). By "craft knowledge", we refer to "that part of professional knowledge which teachers acquire primarily through their practical experience in the classroom" (Brown \& McIntyre, 1993, p. 17). In particular, research may be able to contribute to professional efforts directed towards successful technology integration by making more visible the relevant craft knowledge that expert teachers have developed. In the case study reported here, we examine the craft knowledge underpinning the classroom practice of a teacher who is professionally highly regarded and considered to be expert in integrating use of technology in teaching mathematics lessons.

\section{Theoretical framework}

The Structuring Features of Classroom Practice (SFCP) (Ruthven, 2009) framework was chosen to guide this research. While there are different conceptions of teacher knowledge and learning, the SFCP framework is developed on the assumption that "over a period of time experienced teachers have acquired substantial practical knowledge about teaching, largely through their classroom experience rather than their formal training” (Brown \& McIntyre, 1993, p. 12). Ruthven's (2009) framework highlights features that have been identified as structuring classroom practice and so shaping the professional learning related to teaching as "craft" (e.g., Grimmett \& MacKinnon, 1992; Grimmett, MacKinnon, Erickson, \& Riecken, 1990; Leinhardt, 1990). Drawing from prior research on teaching in general and on early studies of technology integration, the framework identifies five structuring features of classroom practice, which bear crucially on incorporation of technology within classroom practice. These are working environment (e.g., Horne-Martin, 2002; Rivlin \& Weinstein, 1984), resource system (e.g., Cohen, Raudenbush, \& Ball, 2002), activity format (e.g., Burns \& Anderson, 1987), curriculum script (e.g., Leinhardt, Putnam, Stein, \& Baxter, 1991; Putnam, 1987) and time economy (e.g., Assude, 2005). These key structuring features of classroom teaching indicate the corresponding aspects of professional reasoning and craft knowledge that teachers must develop in order to successfully incorporate new technologies (see Table 1).

The challenge to researchers is to help make such craft knowledge more widely accessible: "while we recognize that there are those with mastery of some aspects of teaching, we have no coherent account of what they are masters of and how they achieve what they achieve" (Brown \& McIntyre, 1993, p. 13). Therefore, by examining and probing teachers' classroom practice involving technology use, researchers can help to elicit the thinking behind such practice and articulate the corresponding knowledge. The focus of such analysis is, then, on teaching, viewed from the perspective of the teacher. In terms of teacher professional development, case studies such as the one presented here allow successful teaching approaches to be more widely shared. In addition, the generic analytic framework which has guided this particular case study provides an organising structure which teachers and teacher educators could employ more widely to access craft knowledge about key aspects of classroom practice underpinning innovative examples of teaching with digital technologies. 
Table 1 Components of the structuring features framework (adapted from Ruthven, 2014, p. 387)

\begin{tabular}{|c|c|c|}
\hline $\begin{array}{l}\text { Structuring } \\
\text { feature }\end{array}$ & Defining characterisation & $\begin{array}{l}\text { Examples of associated craft knowledge related } \\
\text { to incorporation of digital technologies }\end{array}$ \\
\hline $\begin{array}{l}\text { Working } \\
\text { environ- } \\
\text { ment }\end{array}$ & $\begin{array}{l}\text { Physical surroundings where lessons take place, } \\
\text { general technical infrastructure available, } \\
\text { layout of facilities, and associated } \\
\text { organisation of people, tools and materials }\end{array}$ & $\begin{array}{l}\text { Organising, displaying and annotating materials } \\
\text { Capturing or converting student productions } \\
\text { into suitable digital form. Organising and } \\
\text { managing student access to, and use of, } \\
\text { equipment and other tools and materials } \\
\text { Managing new types of transition between } \\
\text { lesson stages (including movement of } \\
\text { students) }\end{array}$ \\
\hline $\begin{array}{r}\text { Resource } \\
\text { system }\end{array}$ & $\begin{array}{l}\text { Collection of didactical tools and materials in } \\
\text { use, and coordination of use towards subject } \\
\text { activity and curricular goals }\end{array}$ & $\begin{array}{l}\text { Establishing appropriate techniques and norms } \\
\text { for use of new tools to support subject } \\
\text { activity } \\
\text { Managing the double instrumentation in which } \\
\text { old technologies remain in use alongside new } \\
\text { Coordinating the use and interpretation of tools }\end{array}$ \\
\hline $\begin{array}{l}\text { Activity } \\
\text { structure }\end{array}$ & $\begin{array}{l}\text { Templates for classroom action and interaction } \\
\text { which frame the contributions of teacher and } \\
\text { students to particular types of lesson segment }\end{array}$ & $\begin{array}{l}\text { Employing activity templates organised around } \\
\text { predict-test-explain sequences to capitalise } \\
\text { on the availability of rapid feedback } \\
\text { Establishing new structures of interaction } \\
\text { involving students, teacher and machine and } \\
\text { the appropriate (re)specifications of role }\end{array}$ \\
\hline $\begin{array}{l}\text { Curriculum } \\
\text { script }\end{array}$ & $\begin{array}{l}\text { Loosely ordered model of goals, resources, } \\
\text { actions and expectancies for teaching a } \\
\text { curricular topic including likely difficulties } \\
\text { and alternative paths }\end{array}$ & $\begin{array}{l}\text { Choosing or devising curricular tasks that } \\
\text { exploit new tools, and developing ways of } \\
\text { staging such tasks and managing patterns of } \\
\text { student response } \\
\text { Recognising and responding to ways in which } \\
\text { technologies may help/hinder specific pro- } \\
\text { cesses and objectives involved in learning a } \\
\text { topic }\end{array}$ \\
\hline $\begin{array}{l}\text { Time } \\
\text { economy }\end{array}$ & $\begin{array}{l}\text { Frame within which the time available for class } \\
\text { activity is managed effectively so as to } \\
\text { convert it into components of "didactic time" } \\
\text { contributing directly to desired student } \\
\text { learning }\end{array}$ & $\begin{array}{l}\text { Managing modes of use of tools so as to reduce } \\
\text { the "time cost" of investment in student } \\
\text { familiarisation with them or to increase the } \\
\text { "rate of return" in terms of student learning } \\
\text { Fine-tuning working environment, resource } \\
\text { system, activity structure and curriculum } \\
\text { script to optimise the return on time } \\
\text { investment in terms of student learning }\end{array}$ \\
\hline
\end{tabular}

\section{Research design}

This research took the form of a case study, with the investigation designed accordingly in terms of specifying the case concerned, and selecting methods of data collection and analysis.

\subsection{Specification of the case}

GeoGebra is an open-source educational software package, which provides dynamic mathematical representations (Hohenwarter \& Preiner, 2007). While there is evidence of considerable professional interest in the use of tools such as GeoGebra amongst secondary mathematics teachers in England, how best to develop such use and integrate it into ordinary teaching practice is not yet well understood (Jones et al., 2009). Thus, this paper examines the practice 
of a teacher recognised as having successfully developed and integrated use of GeoGebra in his classroom practice.

The teacher concerned, Chris (pseudonym), was originally approached to participate in the first author's master's study because he was recognised professionally as an expert technology user who employs new technologies in an innovative way in mathematics teaching. Later, Chris was approached again so that his practice could be investigated further, as part of the first author's doctoral study. Chris has around 20 years of teaching experience, is an active member of the GeoGebra community and holds a position as an Advanced Skills Teacher-a recognised grade of classroom teacher within the English school system, with special responsibility for leading professional development.

On each occasion, after Chris had agreed to participate in the research, the first author - the lead researcher in these studies-visited his school to discuss his timetable and to find out when he was planning to make significant use of GeoGebra in his teaching. Observations and interviews then took place as agreed in advance with Chris at his convenience. While the researcher made no attempt to influence the teacher's lessons, it was clearly possible that his planning might be influenced by the knowledge that these lessons would be observed. To try to forestall this, the researcher emphasised to Chris that he himself should choose the topic, using GeoGebra however he saw fit, and in any manner he wished.

Chris chose to teach two topics referred to in the English curriculum as "Transformations" and "Circle Theorems". In 2012, he taught Transformations over a series of seven lessons to a year 9 class of high attaining students (a "top set" in local parlance). In 2014, he taught Circle Theorems to the same class, now in year 11, over a series of six lessons consisting of two lessons in which GeoGebra was not used and four in which it was.

\subsection{Methods of data collection}

\subsubsection{Teacher interviews}

Post-lesson interviews were conducted with the teacher in order to clarify the observed lessons and the professional thinking behind them. Typically, these interviews took place after every second session observed with the intention of avoiding them becoming overly repetitive. A semi-structured interview format provided a degree of flexibility enabling — on the one handthe teacher to talk expansively about the topic while - on the other hand-allowing the interviewer to make sure that key topics were covered and to steer responses back if they strayed too far from the agenda. Interview questions mainly focused on each element of the SFCP framework in turn, as well as exploring how using technology in the lesson might make it rather different to organise and run from a similar lesson in which technology was not being used. Nevertheless, to forestall a potential danger of focusing exclusively on the five constructs of the SFCP framework, in the last part of the interview, the teacher was invited to talk about "any important issues involved in working with this technology that you haven't had an opportunity to talk about so far". The interviews were audio-recorded and transcribed.

\subsubsection{Classroom observations}

A semi-structured, non-participant observation approach was adopted for which the SFCP framework as an interpretative lens provided general guidelines. This made it possible "to have an agenda of issues and gather data to address those issues, [but] in a far less predetermined or 
systematic manner than structured observation” (Cohen, Manion, \& Morrison, 2007, p. 397). Some aspects were pre-specified for particular attention:

- The settings in which the teachers were working and arrangement of these settings

- Resources available in these settings and those made use of

- Coordination of different resources

- How and by whom these resources were used

- Teaching strategies and methods used to incorporate the technology into the lesson

- Types of interactions between teacher, students and technology during a lesson

- The sequence of tasks that students were set over the course of lessons

- How the time available for a lesson was used for students' learning

- Any time-related issues with regard to using new technologies during lessons

- Relationships between these aspects

All observed lessons were also audio-recorded and transcribed. To assist this, the teacher was asked to wear a microphone during lessons in order to capture speech during individual teacher-student interactions.

\subsection{Data analysis}

The audio-recordings of interviews and lessons were transcribed. The transcription process focused on conveying the verbal content of speech so as to capture "the meanings and perceptions created and shared during a conversation" (Oliver, Serovich, \& Mason, 2005, p. 1277 ) without attempting to record every nuance of accentuation or breakdown in flow of expression.

Initial coding of the resulting data was based on the five constructs in the SFCP framework as characterised and exemplified in the available literature. The benefit of framework analysis became clear in this process since it provided systematic and visible stages to the initial analysis of large amounts of data. However, giving the teacher an opportunity to comment more broadly in the last part of the interview provided a check on whether the framework adequately covered relevant issues.

After listening to the recordings and reading the transcriptions several times in order to make sure that nothing would be overlooked, relevant extracts were coded according to the key themes of the conceptual framework. Where an extract related to more than one theme, it was coded accordingly. Researchers (Miles \& Huberman, 1994; Yin, 2009) have pointed out that having a conceptual framework to start with to some extent guards against data overload since it provides systematic and visible stages to the initial analysis without constant comparing and contrasting of large amounts of data. In line with Flick's (1998) description of theoretical coding, then, interpretation of the data consisted of three stages: selective coding, open coding and axial coding. We have already described the first stage of selective coding in terms of the five constructs of the SFCP framework. Then, within these selective categories, a second stage of open coding of material prepared the way for a third stage in which subthemes were identified through a process of axial coding involving a coordinated process of grouping open codes and breaking down selective codes to create the subthemes.

The use of a variety of instruments for data collection made it possible to enhance the trustworthiness of the findings. In order to cross-check conclusions being drawn, triangulation was employed. A particularly important form of triangulation was between teacher 
interviews and classroom observations. The strength of observational data is that it provides the researcher with more direct evidence about classroom events to lay alongside the account of such events provided by the teacher in post-lesson interview. The strength of the interview is that the researcher can probe the teacher's thinking and reasoning. With the aim of understanding phenomena as fully as possible, evidence from interviews and observations was compared and synthesised. For example, a direct quote of the teacher from an interview, a verbatim transcript of a lesson and a screenshot of a student's computer display were used in establishing the presence of a distinctive activity format, Predict-and-test (see section 4.3 Activity format).

Drawing on these analyses, a summary collection of key pieces of evidence was established from which to construct an overarching account of this teacher's classroom practice with GeoGebra. This collection consisted of the following:

- Descriptions of our classroom observations (triangulated by the audio recordings)

- Verbatim transcripts for key episodes in lessons

- Direct quotes from teacher interviews

- Screenshots of the teacher's and/or students' technological display for key episodes within the lesson

- Photographs of the teacher's written board work

- Photographs of students' written work

Where other concepts in the literature on mathematics teachers' use of digital technologies appeared to have direct relevance to the analysis and add clear value to it, we made use of them. In particular, in respect of the activity structure construct, we drew on the empirically based model of instrumental orchestrations developed by Drijvers, Doorman, Boon, Reed, and Gravemeijer (2010) to capture a similar aspect of teacher practice in this study. This reflects the wider spirit that researchers should seek to establish connections between emergent theories (Prediger, Bikner-Ahsbahs, \& Arzarello, 2008).

\section{Results}

In line with the approach taken to analysis, results will be presented in sections corresponding to each of the organising constructs provided by SFCP, and, within each of these sections, in terms of important subsidiary themes that emerged from analysis of the relevant data. Nevertheless, as has been intimated and will become apparent, there is sometimes a degree of interaction between the organising constructs.

\subsection{Working environment}

The two sets of lessons took place in different rooms. Both rooms were specifically designed for computer use enabling the teacher to shift between two working arrangements during the course of a lesson: one arrangement in which students worked in pairs at the computers positioned against the walls, and another arrangement in which students sat together on the seats in the centre of the room. Chris considered this flexibility to be a prominent quality of these working environments, which made it possible to involve students in whole-class activity led by the teacher without their getting distracted by having computers in front of them. 
Both rooms were essentially a combination of a classroom and a computer suite. The Transformations lessons took place in a room (see Fig. 1) where there were a number of computers against one wall (room 1) whereas the Circle Theorems lessons occurred in a room (see Fig. 2) where computers were arranged around the back and side walls in a $U$ shape so that students working at them were facing away from the front of the room (room 2). This permitted the teacher to assign students to work in pairs or small groups at a computer. In both rooms, there was sufficient seating in the centre to accommodate the entire class, facing towards the front of the room where there was a computer connected to a data projector for the teacher, and an interactive whiteboard (subsequently referred to as IWB). By calling students to these seats, the teacher could undertake normal whole-class activity. In this respect, he had developed his craft knowledge for working with technology in these rooms in terms of managing new types of transition between lesson stages and the associated movement of students.

Chris drew attention to two other features of the working environment that were important to him. The first feature was the ease with which he could monitor students' screens while they were working at the computers. He reported that the U-shaped room 2 was more convenient, because he could find a position from which all the students' screens were visible to him, allowing him to intervene more effectively if necessary:

I can see all of their screens. So if I stand in the middle and turn my head I can see everybody's screen which means that I know immediately if somebody isn't doing what they should.

\section{COMPUTERS}

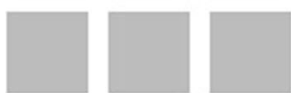

\section{INTERACTIVE} WHITEBOARD
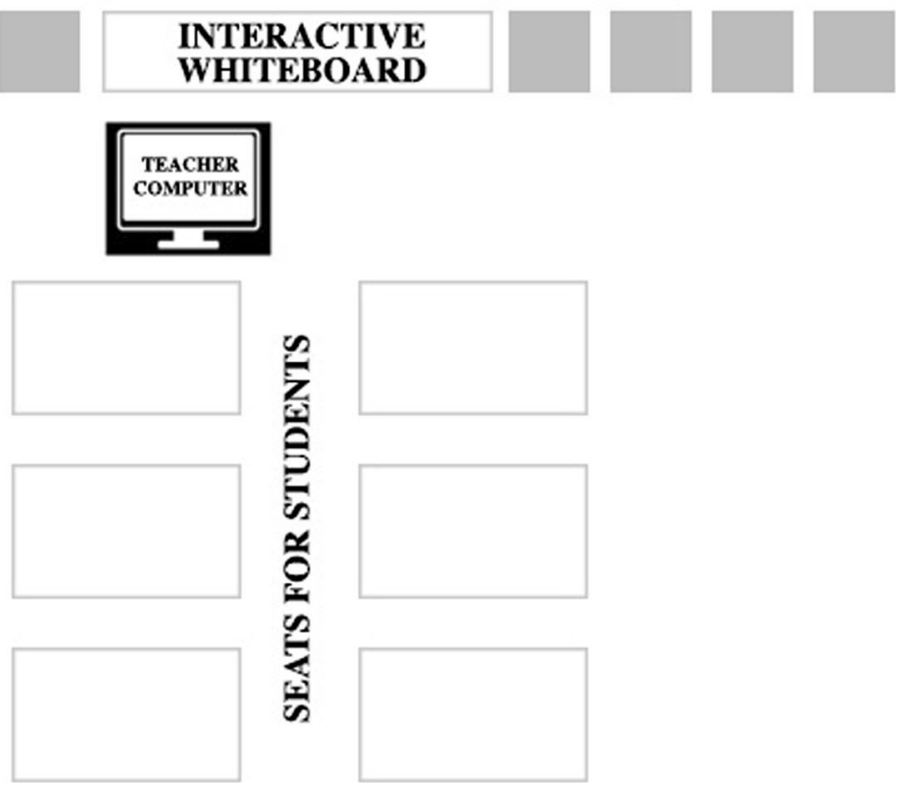

Fig. 1 Layout of the room where Transformations lessons took place 


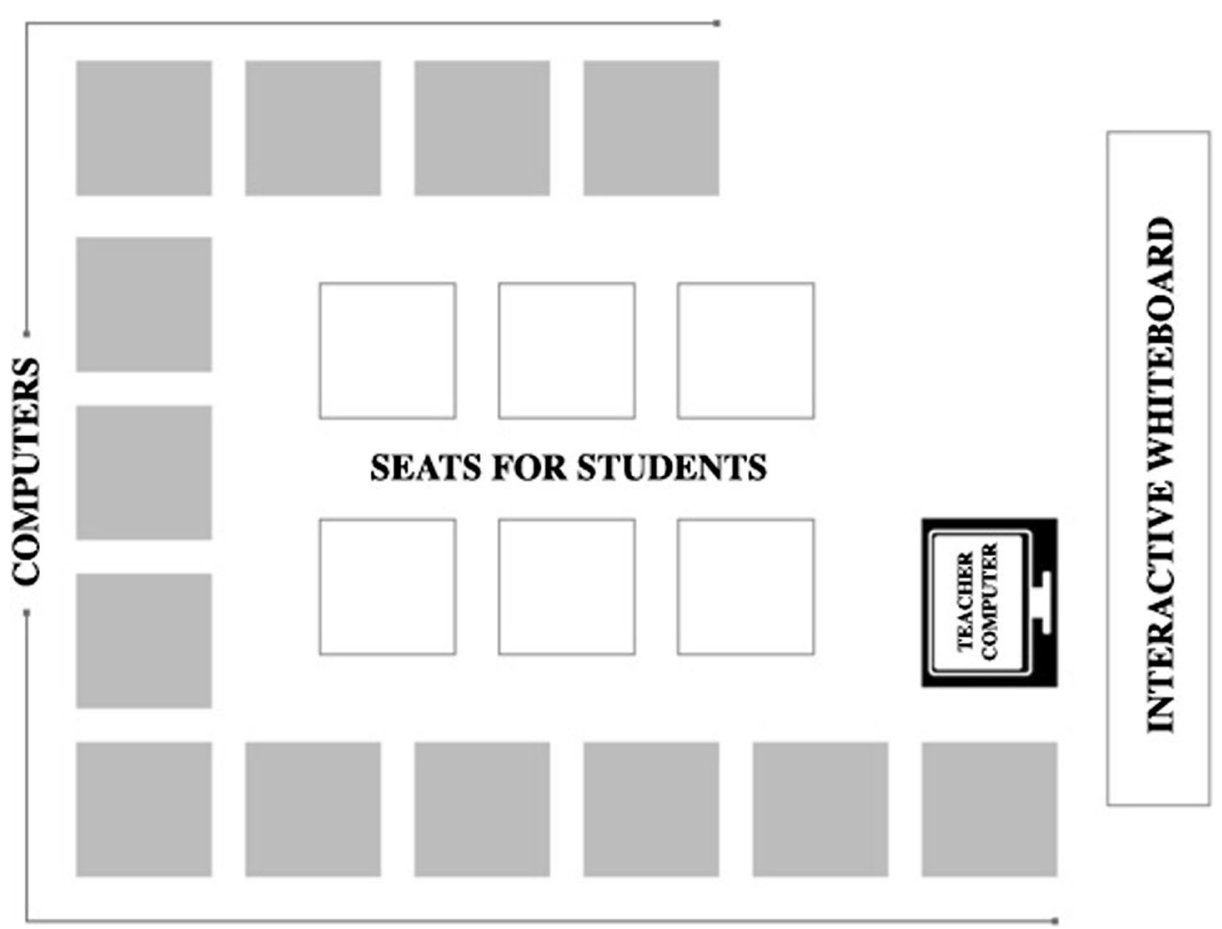

Fig. 2 Layout of the room where Circle Theorems lessons took place

Another feature of working environment that was important to Chris was the facility to be able to display examples of students' work to the whole class. During the lessons in room 1, he would photograph the screen display of a group of students with his mobile phone and project the image onto the IWB:

At the very beginning of the lesson there were two girls showed me their homework, just as I walked past their table. It was so lovely they had done very different things. What they'd done was very impressive. I adapted my ideas for the lesson and took a photo of their work and then projected that to show everybody else.

However, if Chris wanted to exploit any interactive dynamic properties of the students' diagram, there was no alternative to saving it from the student's computer onto the network and then uploading it onto the teacher's computer. In room 2, however, Chris could make use of the network control software available there. Thanks to this software, he could choose to immediately display a student's screen on the IWB for everyone to see, or, he could blank everybody's screen and replace it with the chosen display. Since, when he spotted interesting work, this software made it possible to display students' screens much more easily and quickly, it helped him to implement the associated type of activity format in a more straightforward way, which also improved time economy.

I also liked the fact that it has got the software that'll let me spotlight what pupils had done. And again in the other computer room (Room 1) children had to save their work, I 
then had to load it up. That made it very awkward whereas here I can just click and I can spotlight one pupil's work which is wonderful.

\subsection{Resource system}

The resource system for both topics involved dynamic GeoGebra files. Additionally, for Circle Theorems lessons, students were expected to work initially on paper-and-pencil tasks since Chris saw this as a first stage of the learning process for this topic. Three subthemes emerged, reflecting different aspects of Chris's craft knowledge in relation to working with this resource system.

\subsubsection{Affordances of GeoGebra for supporting learning}

Chris was clear about the crucial qualities of GeoGebra, which supported the discoveryoriented style of task sequence that he used with students. The benefits he associated with these qualities correspond closely to what practitioners have identified as affordances of digital tools and resources in earlier research (Ruthven \& Hennessy, 2002; Ruthven, Hennessy, \& Brindley, 2004). First, the accuracy and speed of GeoGebra facilitated the construction, modification, manipulation and measurement of figures by students, on which these types of task depended:

It allows the exploration. It is very quick. Finding a point, doing that in reverse, finding the mirror line, finding the centre of rotation, scale factor of enlargement is more awkward on paper. Finding centre of the rotation for example is much more difficult on paper. I think pupils get stuck and get bogged down with mechanics of using a compass and using it really accurately whereas GeoGebra let us do that so much more straightforwardly, does not take away from the thinking they need to do but allows them to think... And the fact that we can drag and make changes as well adds an extra dimension to it.

This exploratory style depended on the ease with which GeoGebra not only allowed possibilities to be tried out, but enabled what proved to be false moves to be undone:

Beyond that I think GeoGebra also allows us to be freer with things. If you drag something and it does not work, you can do ctrl $\mathrm{z}$ for undo and it is back. On a piece of paper if you got a diagram and you put an extra line on it and it is the wrong line you are going to try to rub that out or start again. That takes a lot of time. I think it is easier to make mistakes... And it is easier to try things out if you have got GeoGebra. And so I think it helps like that as well. So I think it helps pupils to take more risks. So that is GeoGebra.

Consequently, Chris considered that the feedback available in the GeoGebra task environment enabled students to take greater responsibility for thinking through mathematical situations for themselves:

Pupils having ideas and then testing them are very easy with GeoGebra. For students to be able to think, try it and for them to be deciding what it should be without me needing put a cross in his book and say 'this is wrong, try again' and it gives them a chance to be in control and I hope gives them a chance to behave like mathematician to try things out, 
to explore things and then 'that did not work, try this', 'you solved the problem' and then it works.

\subsubsection{Handling technico-mathematical conventions of GeoGebra operation}

For the Transformations lessons, this particular class was using GeoGebra for the first time and so one of the aims of the first lesson was for students to become accustomed to the software. To accomplish this, Chris began the lesson by demonstrating how to operate the software: how to open the software, where to find the prepared files and where the Toolbar and related Toolbox in a GeoGebra window was located. Also, he showed how to use the dragging function of GeoGebra in order to update positions of a figure dynamically.

Recognising the complexity of the software, Chris had designed files relating to the topic of geometrical transformations for the students to explore this topic. The dynamic files for use by students over the first five lessons involved a carefully graduated development of GeoGebra techniques so that in the last two lessons students could be able to create their own files for which Chris also provided an accompanying instruction worksheet guiding students towards what they were expected to do.

I wanted them to be able to have an accurate slider and just to move the slider and to see the changes immediately. It meant they were focused on the enlargement and on the slider. So, I suppose it was a time saving device.

Chris was also keen to ensure that students would have sufficient time to focus on thinking about the mathematics that he intended them to learn, thus supporting their learning time.

When Chris taught Circle Theorems to the same class 2 years later, most of the students were already familiar with the software. However, he was aware of difficulties that might arise with students' use of GeoGebra for this specific topic, and so he allocated around $15 \mathrm{~min}$ of "tool time" at the beginning of the first lesson where students played with the software and figured out the operation of specific tools relating to angle properties, in particular for measuring angles. During this period, he monitored students and provided feedback when needed. Over the years, he had identified particular issues on which students were likely to require guidance. First, he had noticed that students often use GeoGebra to "measure" without clicking in the standard anti-clockwise order, a technico-mathematical convention embedded in GeoGebra. Second, students needed to be shown how to measure angles formed by two intersecting segments. Third, he specifically reminded students that they could undo an operation that has not produced the desired effect by using Control $+\mathrm{Z}$.

\subsubsection{Making links between different resources}

Chris started teaching Circle Theorems in a paper-and-pencil environment (see Fig. 3) before students moved onto computers to use GeoGebra. Students were expected to work with the dotted circles to draw triangles and calculate angles. The aim was for students to learn to interpret the diagrams through building them up by themselves. This was of crucial importance for students first to have a concrete understanding of diagrams. 
Fig. 3 Chris's worksheet for students to work on without GeoGebra

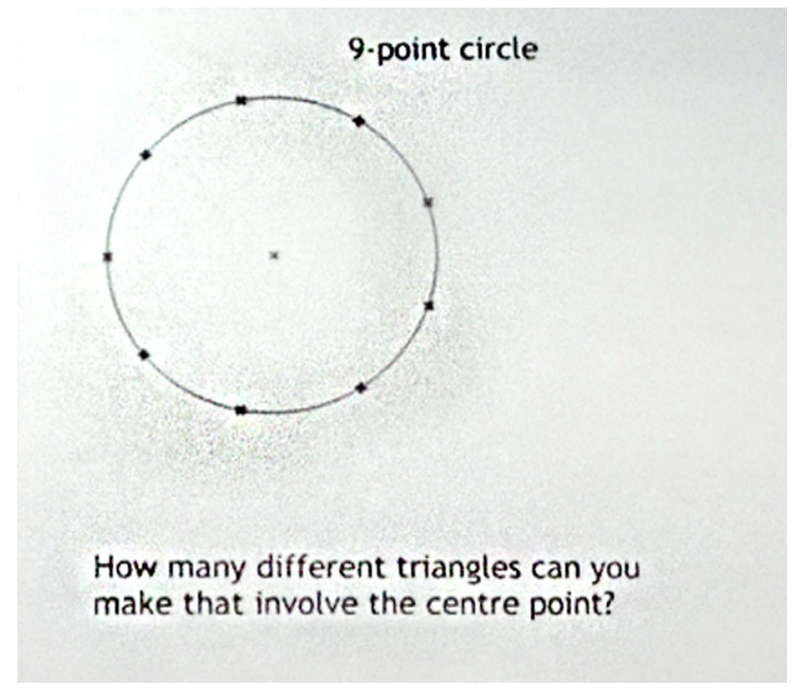

I think it is very important that we don't immediately jump to abstract representations and that we do allow pupils to create their own things in the medium that they are comfortable with.

After the non-technology lessons, students started working in GeoGebra with the aim of producing more examples, thus making conjectures about the relationships between angles in a circle without dots.

We use GeoGebra to gather more information so they can start making conjectures alongside learning the circle theorems stuff. We are also learning about conjecturing, proof, and evidence. That is the idea.

In the case of Transformations, Chris had established, in year 7, the pupils' initial understanding of what reflection is through use of a mirror, and of what rotation is through use of (transparent) tracing paper (superposed on a shape to make a copy of it and then manipulated to show transformation of the shape). He believed that, by the time that students got to year 9, "GeoGebra offers the opportunity to do things that would be very difficult without", such as "to make changes to a diagram very quickly... to create a diagram quickly... to make mistakes and click Control $\mathrm{Z}$ and undo very quickly, which on paper is very awkward and very difficult" in order to give them an extra level of insight into what symmetry is. In this regard, the teacher envisaged these lessons as building on previous work that had been carried out on the topic using classical tools. He thought that dynamic mathematics software brought new diversity to ideas to be developed and representations to be employed when teaching this topic to year 9.

For both topics, Chris used open-ended tasks, which aimed to encourage students to use GeoGebra to provide tools or representations to help their thinking. With this particular class, which was a high-attaining group of students, he had built up this way of working over years. His aim was to show students that there were many paths to reach the same mathematical conclusion: in particular, he saw the topic of Circle Theorems as a vehicle for developing ideas about mathematical proof by focusing on different ways of proving. 


\subsection{Activity format}

While the SFCP framework notes the way in which classroom activity is organised around particular activity formats for interaction between teacher, students and resources, it does not provide any taxonomy of these. However, a useful contribution towards such taxonomy has been developed as one aspect of the theory of Instrumental Orchestration (e.g., Drijvers, 2012; Drijvers, Doorman, Boon, Reed, \& Gravemeijer, 2010). Drijvers' classification of classroom instrumental orchestrations links some layout of the working environment and resources available (a didactical configuration) to an activity format (its exploitation mode). Applying the lens of "instrumental orchestration" to teaching practices involving the use of applets, Drijvers et al. (2010) identified six orchestration types for whole-class teaching: Technical-demo, Link-screen-board, Discuss-the-screen, Explain-the-screen, Spot-and-show and Sherpa-at-work. Additionally, a Work-and-walk-by type was observed during lesson segments where students work individually or in pairs with technology (Drijvers, 2012). Aiming to further develop the framework, Drijvers, Tacoma, Besamusca, Doorman, and Boon (2013) elaborated Work-and-walk-by, identifying five more particular types. In this respect, taking the Instrumental Orchestration model as a point of departure, this paper aims to identify further activity formats specific to the use of technology, in particular where the students are active in exploration with dynamic mathematics software.

Chris's lessons broadly broke down into three phases. Initially, he introduced lessons to the whole class: typically this involved him doing a relevant software demonstration on the IWB, and giving students information about what they were expected to do, and sometimes projecting a student's example for whole class discussion. The dominant formats during this phase were Technical-demo and Explain-the-screen. In the second phase, students went onto the computers and worked with prepared files-in pairs or small groups - to explore Transformations/Circle Theorems using dynamic mathematics software while the teacher was walking around to guide or structure what they were doing. The dominant format during this phase was Work-and-walk-by.

One clear indication of the way in which Chris had developed his craft knowledge was in establishing new structures of interaction involving students, teacher and the software. During Work-and-walk-by, he encouraged students to make their own conjectures and then test them out on the computer, in what could be regarded as creating a distinctive Predict-and-test activity format in which students made predictions which they tested at their computer, using the results either to confirm the reasoning behind their prediction or guide them in refining it. An example provided by Chris at interview (and triangulated against the corresponding part of the observational record for the lesson, including a verbatim transcript of the relevant exchanges and screenshots from the computer involved) was as follows:

There was Ben with his excellent centre of enlargement but error with the scale factor. I deliberately let him make the mistake and then suggested him just check it. I deliberately left him to it. So he would first of all realise that checking was important. He would realise that he made a mistake and then wanted to sort it out; I did not tell him what he had done wrong. (Chris)

Finally, at the end of each lesson, the teacher gathered the whole class together in the middle of the room in order to discuss and connect their independent work to the main ideas of 
the lesson and create collective knowledge. The dominant format during this phase was Spotand-show, which he perceived as a means to enhance student involvement and discussion. This involved him showing examples of students' work, which he had previously spotted, chosen to illustrate different approaches, for discussion with the whole class. In other words, during this closing of each lesson, the teacher's aim was to make sure that the students would see the important points of the lesson and - by sharing spotted examples - different ways of solving the problem in focus.

However, Chris had also developed a more student-centred variant of Spot-and-show. On one occasion in Transformations lessons, he asked students to stand up and walk in a clockwise direction around the room to see different people's screens and then to implement some of the things they thought were useful for them. This was about students spotting interesting examples for themselves rather than the teacher spotting and showing, which could be characterised as Walk-and-spot. This adds a new orchestration type to those that Drijvers has already identified.

Additionally, although not using the term, Chris made use of a Sherpa-at-work format in which the teacher nominates one student (the so called "Sherpa") to operate a computer, with its screen projected for the whole class to see, either to present their own work or to carry out actions requested by the teacher (Drijvers et al., 2010; Trouche, 2004). Using a similar process to Spot-and-show, the teacher would spot an example of student work at their computer while circulating in the classroom, and then have it projected on the IWB for whole class discussion. The student concerned (the owner of the spotted example) would sit at their computer, responsible for operating it in response to the teacher's requests. In the meantime, the teacher would remain at the front using question and answer to explain the projected example to the class and asking the (Sherpa) student to carry out specific actions in the technological environment.

It was very interesting that she (the student demonstrating the spotted example) was moving the point and she was doing the demonstrating but I was pushing on what was going on. I was making sure that I was emphasising the things that I found very important.

Chris argued this specific activity format was distinctive to technology use.

That was a really nice way of doing that because she (the student demonstrating the spotted example) was able to be absolutely fully involved. I was asking her to do particular things I knew they would be helpful. We could then talk about as a class. Yeah that was particularly exciting and that of course can't happen without the technology.

\subsection{Curriculum script}

This section analyses how Chris' curriculum script for teaching these topics had developed in response to using GeoGebra. We have focused on those parts where Chris reported change and development in his thinking about teaching these topics and structuring lessons arising from his reflection on experience of using GeoGebra for this purpose. In particular, he had come to realise how treatment of this subject matter might need to change so as to respond adequately to its mediation by GeoGebra. 
In the case of Transformations lessons, Chris reported how experience of teaching with GeoGebra had changed his thinking about the logic of development of this topic, notably the way in which it had led him to see the value of discussing the special scale factors 1 and 0 in enlargement.

It never occurred to me give them a question where it says enlarge it by scale factor 1 because the idea in a textbook or on a worksheet, enlarge it scale factor 1 , that is just waste of space, it doesn't do anything, nothing changes. Whereas it was using GeoGebra made me realize that really is important. It is the identity. It is the multiplicative identity. I now make a big deal with my pupils about it. Beyond 0, lower than zero there is a rotation happening as well and then enlargement of some kind. That followed on nicely. But the real breakthrough for me was scale factor 1 . Scale factor 0 then fell into place quite quickly whereas the one that surprised me was scale factor 1 .

Likewise, Chris reported how his appreciation of teaching Circle Theorems had changed over the years. From his initial experience, it became clear to him that using prepared files for each Circle Theorem with step-by-step instructions did not succeed in making students fully engage and interact with diagrams.

I found that (structured prepared files) much less powerful because to start with there were lots of instructions. They were treating it as a bit like what shape is this, or what colour is that or they were giving a one-word answer that was forgotten immediately because it was not important and then move to the next one. What I have planned to be a week of work, they did in about 10 min because they went through every single thing and then said I have finished.

Additionally, he noticed that students were generally having difficulties in making links between dynamic GeoGebra diagrams and static diagrams on paper. For these reasons, he returned to having students start with pencil and paper work through which they could build up a concrete understanding of angle properties of circles before embarking on GeoGebra work where they would interact with dynamic figures capable of generating multiple examples.

I expected that they would see a static diagram with two angles on has been the same as each other because we could drag this mentally but they didn't see that. And that is one of the reasons I now start on paper. We start building from ground up rather than me giving them diagrams to interact with.

Chris mentioned a Circle Theorems file that he had used before in which the rounding was set to show whole number values. He became concerned that working with this file created confusion for students due to rounding errors. Eventually, however, he adapted his approach so as to purposefully make use of this apparent anomaly to generate whole class discussion which would make students think about rounding.

One particular example is with a file showing the angle at the centre and the angle at the circumference. I had a problem with it where it will show something like 51 and 103. I decided this was very bad because the students might think that actually it is not double. After that, it was about a year later I suddenly realized this was really useful because why it does not appear to work because of the rounding errors. I then used this file I deliberately made it there was a problem like this. I asked the pupils what has happened. 


\subsection{Time economy}

Chris divided the timespan of a lesson into the three phases noted earlier: introduction time (whole class), activity time (student individual/group work) and collective knowledge time (whole class), in order to produce overall didactic time.

As a teacher experienced both in teaching and technology use, Chris had developed a number of time-saving strategies that helped to manage the pace of activities and to use time efficiently. At the beginning of the first lessons on each topic, he spent the activity time for students on learning to make use of the software (tool time). In order to use the tool time economically, he first did Technical-demo so that students could learn how to find and open the software on their computer and then to introduce specific tool features. For Transformations lessons, he provided the students with prepared files to work on, which helped him to have control over didactic time, since the files were designed by him according to the content that he wanted his pupils to learn. During paired student work at computers, he circulated around the classroom and made "authoritative contributions" (Assude, 2005, p. 201) in order to support progression in students' learning. Another strategy to support the timely progression of all students in the manner that he desired included giving intermediate syntheses. In particular, during Work-and-walk-by, he spotted and showed examples of student work that he thought would be useful for whole-class discussion, with the intention of guiding students through his choice of ideas to consider. Spot-and-show was also used at the beginning of lessons to remind students of where the previous lesson had left off and what they should do next, so helping to use the available time efficiently.

In addition, use of the IWB made whole class teaching easier in the sense that it allowed Chris to demonstrate a number of tool techniques and explain/discuss diagrams with the use of GeoGebra. This, in return, helped him to make efficient use of time. Furthermore, IWB use enabled him to record, save and display all the conjectures that students had made. This was particularly useful both in terms of managing display space during the lesson and permitting him to return to the saved conjectures in future lessons, again making the working process efficient in terms of time.

There is also an issue of space. We got five different conjectures and could scroll up and down whereas on an ordinary board you couldn't do that. But I have saved those and I now got those and get back to them tomorrow and that is useful as well. If they are written on an ordinary board we have to re write them again tomorrow.

\subsection{Other issues}

In response to the invitation to comment on issues not covered by the earlier interview questions (which were directly related to the components of the SFCP framework), Chris noted the importance of his having become confident in handling what had initially been unexpected and perturbing situations arising in connection with use of technology during lessons; the type of situations that Clark-Wilson (2013) has referred to as "hiccups". Chris's post-lesson interviews provided evidence that he recalled lesson hiccups that he had encountered and the ways that he had devised to avoid or manage these. He had, in effect, developed his craft knowledge to reduce uncertainty and disorder by recognising the possibility of such events and devising strategies which made them avoidable or 
manageable. The preceding sections provide many examples of this. Chris's observation, then, was highlighting the process through which his classroom practice and craft knowledge had developed, rather than identifying any unacknowledged structuring feature of that process.

\section{Discussion and conclusion}

We conclude with a summary overview of findings from the case followed by consideration of its professional exploitation and some theoretical reflection.

\subsection{Summary overview}

Each section of the results from this case study has provided evidence of adaptation of teaching practices and development of craft knowledge by this teacher, linked to his appropriation of GeoGebra as an instrument for teaching and learning mathematics.

Chris had developed what were now well-established teaching repertoires associated with use of the software. He planned investigative lessons focused on having students explore and evaluate by means of GeoGebra. For both the topics that he was observed teaching, he wanted students to engage in multiple approaches to problem solving, and so he encouraged them to come up with their own ideas and test them in GeoGebra. This was especially apparent in the lessons where students were guided to investigate and prove conjectures that lead to different circle theorems. The emphasis of Chris's lessons was on helping students to take initiative and develop their higher-order reasoning.

The evidence has indicated how Chris had developed craft knowledge enabling him to establish new structures of interaction involving students, teacher and software. Predict-andtest was the main activity format that he employed for independent work by students with GeoGebra. Similarly, he employed Spot-and-show as the main activity format for whole-class discussion involving joint use of GeoGebra and IWB. By spotting examples of students' work, in particular those illustrating differing approaches, he was able to promote whole-class discussion which enabled him to make "more explicit references to student actions and to test their points within lessons" (Leinhardt, 1991, p. 91). He had developed effective patterns of classroom organisation and management to allow such lessons to proceed smoothly, particularly transitions between these segments of student independent work and whole-class discussion.

Reflecting on the development of his teaching, Chris indicated that GeoGebra had brought about transformative change to his approaches to these topics, which led to his curriculum scripts developing to include new tasks (i.e., the discussion of scale factor 1 and 0 in enlargement) and exploit new activity formats (i.e., Sherpa-at-work) which were previously inconceivable. He had developed the craft knowledge that underpinned his teaching of these topics through fine-tuning his use of GeoGebra over the years to his already "discovery" oriented pedagogical approach. Considering those lessons on Circle Theorems which made no use of GeoGebra, it appears that his approach had already included use of more open-ended tasks and student-centred activity formats (e.g., Discuss-the-board, Spot-and-show and Work-and-walk-by) which he had found easy to adapt when incorporating GeoGebra. For instance, the Spot-and-show format 
was used in these (non-technology) lessons by inviting pupils to come to the board and write down their ideas for discussion with the rest of the class. In Chris' view, the key difference in technology lessons was the new relationship between teacher, student and technology rather than between teacher and student. As he pointed out, the use of Sherpa-at-work in particular was distinctive to technology use because the involvement of the computer gave the interaction taking place a distinctive character. In this respect, his use of Sherpa-at-work and Spot-and-show activity formats represented specific adaptations to exploit the potential of GeoGebra in sharing and discussing student work, to give the whole class better access to different representations of, or solutions to, the same problem.

\subsection{Practical exploitation}

This case could be used to inform teacher professional development and teacher education programmes in the field in accordance with a "building on strength model" (Brown $\&$ McIntyre, 1993) in which innovative examples of teaching practice and the associated craft knowledge are brought to the attention of teachers and teacher educators. While there are circumstances under which such practice and knowledge might be found to be transferable between persons and transposable between contexts-providing practical solutions to specific concrete problems that a teacher commencing integrating technology into their teaching would encounter - the value of such a case does not reside simply in, or indeed depend on, any such replicability. Such a case could equally serve an illuminative function, offering insight into one way of responding to new teaching situations so as to support more informed reflection and practical experiment in relation to them. Thus, at both these levels, the classroom practice and craft knowledge which enabled this expert teacher to make innovative use of GeoGebra have the potential to be of value to other teachers working in similar contexts.

More generally, by identifying key aspects of the craft knowledge underpinning classroom practice in teaching with technology, the SFCP framework-illustrated by examples of findings from studies such as this - could be used to guide student and serving teachers in gaining access to the craft knowledge of appropriately experienced and expert colleagues in school-based components of teacher education and professional development. Finally, for educational researchers, this study has provided a further test of the usability and usefulness of the SFCP framework as a tool for investigating technology integration.

\subsection{Theoretical reflection}

As noted earlier, our analysis made use of further concepts from the literature on mathematics teachers' use of digital technologies. In particular, we appealed to Clark-Wilson's (2013) concept of hiccup in interpreting Chris' response to our invitation to comment on issues that he considered relevant which had not been covered in interview questions relating to the components of the SFCP framework. In effect, his response pointed to how events that he had originally experienced as unexpected and unfamiliar had become recognised possibilities for which he now had appropriate proactions or reactions. This highlights the way in which experience-based craft knowledge accumulates, as a teacher becomes familiar with an increasing range of classroom situations and develops effective ways of managing them. 
We also found it particularly useful to draw on Drijvers' (2010, 2012, 2013) characterisation of types of classroom instrumental orchestration in analysing the activity formats in play during lessons. This raises the question of the relationship between the structuring features (SFCP) and instrumental orchestration (IO) frameworks. Drijvers characterises each type of instrumental orchestration as combining a "didactical configuration" of the teaching setting and the artefacts within it-what SFCP would treat as a combination of "working environment" and "resource system"- and an "exploitation mode" reflecting the form and functionality of interaction between teacher, students and tools-what SFCP would treat as an "activity format". Both frameworks, then, examine the templates for classroom organisation and interaction that teachers employ in making use of the infrastructure and materials available to them. Drijvers also treats each individual episode of instrumental orchestration as having a further component of "didactical performance" constituted by the in-the-moment handling of the intellectual substance of the lesson by the teachersomething which SFCP would consider as the expression on a particular occasion of an overarching "curriculum script" and as conditioned by an underlying "time economy". Here, then, the frameworks differ in the level at which they treat these phenomena: whereas IO places more emphasis on a particular performance, SFCP posits deeper structures guiding such performances. We are conscious that illuminating such generative structures is more challenging than describing related aspects of particular lessons: for example, accessing an overarching curriculum script and confidently identifying development in it, or scope for variation within it, calls ideally for study of a teacher's teaching of a particular topic on multiple occasions over an extended period of time.

At the present stage of development of research in this area, we see heuristics such as those provided by the SFCP and IO frameworks as valuable. However, for longer term development, it will be important to fill out such frameworks through finer-grained analysis of teacher expertise related to incorporation of digital technologies. For example, returning to Table 1, this would call for the third column to shift from offering examples of craft knowledge shaped by one or more structuring factor towards providing something closer to a systematic inventory of such types of knowledge. Indeed, it was precisely because it seemed to provide this finer-grain in relation to activity format that we found Drijvers' itemisation of distinct types of instrumental orchestration useful in this study. Equally, by finding new types of orchestration/format, this study suggests that work remains to be done to establish an exhaustive model. Nevertheless, although relations such as those we have just sketched can be established between the two frameworks, we are conscious that they have distinct intellectual hinterlands: SFCP appealing more to an Anglo-American tradition of research on teaching, IO more to a French tradition of didactical research. It may be that further "networking" (c.f. BiknerAhsbahs \& Prediger, 2014) of these frameworks can produce a widely usable synthesis (c.f. Ruthven, $2014^{1}$ ).

\footnotetext{
${ }^{1}$ This chapter examines and compares the two frameworks considered here and a third one: Technological, Pedagogical and Content Knowledge (TPACK) (Mishra \& Koehler, 2006).
} 
Acknowledgments The authors are extremely grateful to "Chris" for his generous participation in the study. The first author thanks the Ministry of National Education of Turkey for supporting her doctoral studies during which this research was undertaken. We also thank the ESM reviewers and editor for their helpful comments on this paper.

Open Access This article is distributed under the terms of the Creative Commons Attribution 4.0 International License (http://creativecommons.org/licenses/by/4.0/), which permits unrestricted use, distribution, and reproduction in any medium, provided you give appropriate credit to the original author(s) and the source, provide a link to the Creative Commons license, and indicate if changes were made.

\section{References}

Abboud-Blanchard, M. (2014). Teachers and technologies: Shared constraints, common responses. In A. ClarkWilson, O. Robutti, \& N. Sinclair (Eds.), The mathematics teacher in the digital era (pp. 297-317). Dordrecht: Springer.

Assude, T. (2005). Time management in the work economy of a class. A case study: Integration of Cabri in primary school mathematics teaching. Educational Studies in Mathematics, 59(2), 183-203.

Bikner-Ahsbahs, A., \& Prediger, S. (Eds.). (2014). Networking of theories as a research practice in mathematics education. New York: Springer.

Brown, S., \& McIntyre, D. (1993). Making sense of teaching. Buckingham: Open University Press.

Burns, R. B., \& Anderson, L. W. (1987). The activity structure of lesson segments. Curriculum Inquiry, 17(1), 31-53.

Clark-Wilson, A. (2013). How teachers learn to use complex new technologies in secondary mathematics classrooms: The notion of the hiccup. In B. Ubuz, C. Haser, \& M. A. Mariotti (Eds.), Proceedings of the Eighth Congress of the European Society for Research in Mathematics Education (pp. 2544-2553). Antalya: ERME/Middle East Technical University.

Cohen, L., Manion, L., \& Morrison, K. (2007). Research methods in education (6th ed.). London: Routledge.

Cohen, D. K., Raudenbush, S. W., \& Ball, D. L. (2002). Resources, instruction, and research. In R. Boruch \& F. Mosteller (Eds.), Evidence matters: Randomized trials in education research (pp. 80-119). Washington, DC: Brookings Institution Press.

Drijvers, P. (2012). Teachers transforming resources into orchestrations. In G. Gueudet, B. Pepin, \& L. Trouche (Eds.), From text to 'Lived' resources (pp. 265-281). New York: Springer.

Drijvers, P., Doorman, M., Boon, P., Reed, H., \& Gravemeijer, K. (2010). The teacher and the tool: Instrumental orchestrations in the technology-rich mathematics classroom. Educational Studies in Mathematics, 75(2), 213-234.

Drijvers, P., Tacoma, S., Besamusca, A., Doorman, M., \& Boon, P. (2013). Digital resources inviting changes in mid-adopting teachers' practices and orchestrations. ZDM The International Journal on Mathematics Education, 45(7), 987-1001.

Grimmett, P., \& Mackinnon, A. (1992). Craft knowledge and the education of teachers. Review of Research in Education, 18, 385-456.

Grimmett, P., MacKinnon, A., Erickson, G., \& Riecken, T. (1990). Reflective practice in teacher education. In R. Clift, R. Houston, \& M. Pugach (Eds.), Encouraging reflective practice: An examination of issues and exemplars (pp. 20-38). New York: Teachers College Press.

Gueudet, G., \& Trouche, L. (2009). Towards new documentation systems for mathematics teachers? Educational Studies in Mathematics, 71(3), 199-218.

Haspekian, M. (2014). Teachers' instrumental geneses when integrating spreadsheet software. In A. ClarkWilson, O. Robutti, \& N. Sinclair (Eds.), The mathematics teacher in the digital era (pp. 241-275). Dordrecht: Springer.

Hohenwarter, M., \& Preiner, J. (2007). Dynamic mathematics with GeoGebra. Journal of Online Mathematics and its Applications, 7, 1448.

Horne-Martin, S. (2002). The classroom environment and its effects on the practice of teachers. Journal of Environmental Psychology, 22(1/2), 139-156.

Jones, K., Lavicza, Z., Hohenwarter, M., Lu, A., Dawes, M., Parish, A., et al. (2009). Establishing a professional development network to support teachers using dynamic mathematics software GeoGebra. Proceedings of the British Society for Research into Learning Mathematics, 29(1), 97-102.

Leinhardt, G. (1988). Situated knowledge and expertise in teaching. In J. Calderhead (Ed.), Teachers' professional learning (pp. 146-168). London: Falmer Press. 
Leinhardt, G. (1990). Capturing craft knowledge in teaching. Educational Researcher, 19(2), 18-25.

Leinhardt, G., Putnam, R. T., Stein, M. K., \& Baxter, J. (1991). Where subject knowledge matters. In J. Brophy (Ed.), Advances in research on teaching; Vol 2. Teachers' knowledge of subject matter as it relates to their teaching practice (pp. 87-113). Greenwich, CT: JAI Press.

Miles, M. B., \& Huberman, A. M. (1994). Qualitative data analysis: An expanded source book. Thousand Oaks: Sage Publications.

Mishra, P., \& Koehler, M. (2006). Technological pedagogical content knowledge: A framework for teacher knowledge. Teachers College Record, 108(6), 1017-1054.

Monaghan, J. (2004). Teachers' activities in technology-based mathematics lessons. International Journal of Computers for Mathematical Learning, 9(3), 327-357.

Oliver, D. G., Serovich, J. M., \& Mason, T. L. (2005). Constraints and opportunities with interview transcription: Towards reflection in qualitative research. Social Forces, 84(2), 1273-1289.

Prediger, S., Bikner-Ahsbahs, A., \& Arzarello, F. (2008). Networking strategies and methods for connecting theoretical approaches: First steps towards a conceptual framework. ZDM The International Journal on Mathematics Education, 40(2), 165-178.

Putnam, R. T. (1987). Structuring and adjusting content for students: A study of live and simulated tutoring of addition. American Educational Research Journal, 24(1), 13-48.

Rivlin, L. G., \& Weinstein, C. S. (1984). Educational issues, school settings, and environmental psychology. Journal of Environmental Psychology, 4(4), 347-364.

Ruthven, K. (2009). Towards a naturalistic conceptualisation of technology integration in classroom practice: The example of school mathematics. Education and Didactique, 3(1), 131-159.

Ruthven, K. (2014). Frameworks for analysing the expertise that underpins successful integration of digital technologies into everyday teaching practice. In A. Clark-Wilson, O. Robutti, \& N. Sinclair (Eds.), The mathematics teacher in the digital era (pp. 373-393). Dordrecht: Springer.

Ruthven, K., \& Hennessy, S. (2002). A practitioner model of the use of computer-based tools and resources to support mathematics teaching and learning. Educational Studies in Mathematics, 49(1), 47-88.

Ruthven, K., Hennessy, S., \& Brindley, S. (2004). Teacher representations of the successful use of computerbased tools and resources in secondary-school English, Mathematics and Science. Teaching and Teacher Education, 20(3), 259-275.

Tabach, M. (2012). A mathematics teacher's practice in a technological environment: A case study analysis using two complementary theories. Technology, Knowledge and Learning, 16(3), 247-265.

Trouche, L. (2004). Managing the complexity of human/machine interactions in computerized learning environments: Guiding students' command process through instrumental orchestrations. International Journal of Computers for Mathematical Learning, 9(3), 281-307.

Yin, R. K. (2009). Case study research: Design and methods (4th ed.). London: Sage. 